\title{
Salutogênese-Camponês a Camponês: uma metodologia para promoção da saúde de populações expostas a agrotóxicos
}

\author{
Salutogenesis-Peasant-to-Peasant: a methodology for health \\ promotion of populations exposed to pesticides \\ Pedro Henrique Barbosa de Abreu1, Herling Gregorio Aguilar Alonzo²
}

DOI: 10.1590/0103-11042018S421

RESUMO O estudo teve por objetivo apresentar experiência de metodologia para a promoção da saúde de populações expostas a agrotóxicos. Trata-se de um relato de experiência metodológica desenvolvida com camponeses de Lavras (MG), por meio de pesquisa-ação, entre maio e setembro de 2017. Estruturada pelas bases teórico-práticas do paradigma da Salutogênese e da metodologia social de disseminação da agroecologia Camponês a Camponês, a metodologia proposta permite o desenvolvimento do Senso de Coerência dos camponeses e a disponibilização dos recursos agroecológicos presentes nas comunidades rurais, apresentando-se como ferramenta para ações e pesquisas em contextos semelhantes em outras localidades do Brasil.

PALAVRAS-CHAVE Promoção da saúde. Desenvolvimento da comunidade. Agricultura sustentável. Produção de alimentos. Agroquímicos.

1 Universidade Estadual de Campinas (Unicamp), Faculdade de Ciências Médicas, Programa de Pós-Graduação em Saúde Coletiva - Campinas (SP), Brasil.

pedro_hba@yahoo.com.br

2 Universidade Estadual de Campinas (Unicamp), Faculdade de Ciências Médicas, Programa de Pós-Graduação em Saúde Coletiva - Campinas (SP), Brasil.

alonzo@fcm.unicamp.br

ABSTRACT The study aimed to present an experience of methodology for Health Promotion of populations exposed to pesticides. This is a methodological experience report carried out with peasants from Lavras (MG), Brazil, through action-research, between May and September 2017. Structured by the theoretical and practical basis of the Salutogenesis paradigm and the social methodology of Peasant-to-Peasant of dissemination of agroecology, the methodology proposed permits the development of the Sense of Coherence of the peasants and the availability of the agroecological resources present in the rural communities, introducing itself as a tool for actions and researches in similar contexts in other Brazilian localities.

KEYWORDS Health promotion. Community development. Sustainable agriculture. Food production. Agrochemicals. 


\section{Introdução}

Considerada o "marco fundador do movimento da promoção da saúde no mundo"1(12), a Carta de Ottawa ${ }^{2}$, constructo da Primeira Conferência Internacional Sobre Promoção da Saúde, realizada em 1986, apresentou o conceito para um novo campo de conhecimento e prática em saúde. Buss $^{3}$, ao analisar o conteúdo e o desenvolvimento desse conceito, afirma que a promoção da saúde e a prevenção da saúde (com seus métodos que buscam evitar as doenças como forma de garantir a saúde individual e populacional) são complementares, porém

o enfoque da promoção da saúde é mais amplo e abrangente, procurando identificar e enfrentar os macrodeterminantes do processo de saúde-doença, e buscando transformá-los favoravelmente na direção da saúde ${ }^{3(37)}$.

Segundo este mesmo autor, "os indivíduos e as comunidades devem ter oportunidade de conhecer e controlar os fatores determinantes da sua saúde"3(30).

Sendo, nesse sentido, o modelo de produção de alimentos um fator determinante para a saúde de famílias e comunidades camponesas e sendo os agrotóxicos invariavelmente danosos à saúde humana e ao meio ambiente ${ }^{4-7}$, não há outro caminho viável para a promoção da saúde no campo que não o desenvolvimento de um processo social que permita a compreensão e a superação da lógica dominante do modelo de agricultura baseado na utilização de insumos químicos industriais. Assim, a formulação de uma estrutura metodológica para a transição para modelos de produção de base ecológica e sua implementação como um processo social que promova a autonomia e a saúde de populações camponesas expostas à agrotóxicos ${ }^{8-10}$ exigem a utilização de base teórico-prática que fundamente o desenvolvimento dos conceitos da promoção da saúde e que busque, tendo os próprios camponeses como protagonistas desse processo, focar os esforços de ação e pesquisa para a identificação, disponibilização e operacionalização dos fatores presentes nas comunidades e famílias camponesas que, de fato, promovam saúde.

Dessa forma, o presente estudo apresenta um relato de experiência de metodologia em que foram associadas as bases teóricas da Salutogênese ${ }^{11-13} \mathrm{e}$ as bases teórico-práticas da metodologia Camponês a Camponês $(\mathrm{CaC})^{14-}$ 16 de disseminação horizontal da agroecologia, sendo a primeira identificada como paradigma de promoção da saúde que busca levantar, tornar cognoscível e disponibilizar as práticas, conhecimentos e características positivas de uma determinada população e localidade e a segunda, como metodologia social que permite a construção de processos capazes de promover a transição agroecológica em diferentes escalas por meio de princípios e métodos que desenvolvem os intercâmbios de conhecimentos e práticas e o apoio mútuo entre camponeses.

Essa estrutura metodológica, que compõe parte dos trabalhos de campo de tese de doutoramento em desenvolvimento pelo Departamento de Saúde Coletiva da Faculdade de Ciências Médicas da Universidade Estadual de Campinas (Unicamp), vem permitindo a operacionalização de um processo social (gradual e contínuo) de promoção da saúde de camponeses do município de Lavras (MG) e se apresenta como potencialmente exequível e exitosa para desenvolver e implementar estratégias semelhantes de promoção da saúde em outras localidades onde haja contextos de populações camponesas expostas a agrotóxicos.

\section{Referencial teórico-prático}

\section{Salutogênese}

Aaron Antonovsky ${ }^{11}$ desenvolveu os conceitos da Salutogênese ao realizar estudos com mulheres que haviam sido submetidas às condições degradantes dos campos de concentração nazista e ao identificar que, apesar de terem 
vivido situações semelhantes de estresse físico e psicológico, algumas se mantinham saudáveis e outras não $0^{11,13,17}$. A maneira como cada uma das inúmeras experiências vivenciadas ao longo da vida (sejam elas negativas ou positivas) é vista/interpretada por cada pessoa seria, segundo o autor, capaz de afetar a forma de lidar com a tensão e o estresse e também de influir na percepção e utilização de recursos (experiências) próprios para lidar, interpretar e até mesmo beneficiar seu estado saúde ${ }^{11,12}$.

Para Antonovsky ${ }^{\mathbf{1 1}, \mathbf{1 2}}$, então, as práticas, conhecimentos e características positivas desenvolvidas e acumuladas a partir de cada experiência de vida (recursos de saúde) passam a ser, segundo o modelo Salutogênico de promoção da saúde, o embasamento subjetivo e as ferramentas utilizadas pelas pessoas e suas comunidades no processo contínuo de melhora de suas condições de vida e saúde. Qualidades cognitivas, comportamentais e motivacionais são geradas a partir da identificação e apropriação dos recursos de saúde presentes em cada pessoa e em sua comunidade, e estas qualidades, descritas, respectivamente, como sentido de compreensão (entendimento do contexto em que vivem), sentido de manejo (crença de que dispõe e podem utilizar seus próprios recursos) e sentido de significado (motivação para mudar para melhor seu contexto utilizando seus próprios recursos), ao serem fortalecidas, retroalimentam a capacidade das pessoas de identificar e de se apropriar de novos recursos presentes em seu ser e em sua comunidade. $\mathrm{O}$ conjunto desses sentidos é chamado pelo autor de Senso de Coerência (SOC) $)^{11-13}$.

Em consonância com o paradigma da Salutogênese, portanto, a promoção da saúde em qualquer comunidade, independentemente de seu contexto de carências, debilidades e injustiças, apenas será resolutiva e de fato empoderadora caso os esforços de ação e pesquisa sejam direcionados para a identificação, a disponibilização e a utilização dos recursos de saúde ali existentes ${ }^{11-13}$.

No entanto, devido à morte de Aaron Antonovsky (1923-1994) antes de estruturar métodos de desenvolvimento e aplicação dos sentidos de compreensão, manejo e significado e ao persistente foco de pesquisadores subsequentes em trabalhar quase que exclusivamente com a aplicação do Questionário SOC (ferramenta desenvolvida por Antonovsky para medir o SOC individual) ${ }^{\mathbf{1 1}}$ para quantificar tais sentidos em algum contexto específico ${ }^{\mathbf{1 8}, 19}$, a Salutogênese ainda carece de um componente prático que forneça instrumentos que permitam a operacionalização da promoção, do fortalecimento, da consolidação e da aplicação das qualidades e recursos pessoais e comunitários que viabilizem esse paradigma sanitário.

Nesse sentido, para o desenvolvimento de um processo salutogênico de promoção da saúde em comunidades camponesas expostas a agrotóxicos, torna-se fundamental a busca e utilização de métodos que permitam operacionalizar a visibilização das experiências agroecológicas disponíveis em propriedades e comunidades camponesas e, consequentemente, motivar e empoderar os camponeses para a utilização e o intercâmbio horizontal de conhecimentos e inovações agroecológicas. Assim, a Salutogênese encontra na metodologia social $\mathrm{CaC}$ os instrumentos e ferramentas sociais necessários para desenvolver, na prática, todo seu potencial transformador.

\section{Camponês a Camponês}

Tendo seus primeiros passos na América Latina sido dados, a partir de 1972, na Guatemala, a metodologia social CaC percorreu, entre as décadas de 1970 e 1990, diferentes caminhos, organizações e escalas nos campos do México, Honduras e Nicarágua ${ }^{\mathbf{1 5}, 20}$. Todavia, é em Cuba onde, desde sua implementação em 1997, o CaC vem obtendo seus resultados mais expressivos na conversão agroecológica e na sua disseminação. Em apenas 20 anos desde a implementação dessa metodologia pela Associação Nacional dos Pequenos Agricultores (Anap), o CaC possibilitou que $50,0 \%$ dos camponeses e camponesas cubanas passassem a produzir os alimentos que consomem e comercializam de 
maneira equilibrada com o ecossistema local e sem a necessidade de utilização de produtos nocivos à saúde e ao ambiente ${ }^{\mathbf{1 4}, \mathbf{2 0}}$.

Conceitualmente, a construção de processos sociais de disseminação da agroecologia por meio da metodologia $\mathrm{CaC}$ se dá mediante a identificação e compartilhamento de saberes, conhecimentos e técnicas agroecológicas entre os próprios camponeses, sendo essa identificação e esse compartilhamento viabilizados pela organização social entre as famílias das comunidades rurais de um território. Cinco princípios fundamentais guiam esse processo de disseminação (quadro 1):

Quadro 1. Princípios que guiam a metodologia Camponês a Camponês

\section{Princípio 1 Começar devagar e em pequena escala \\ Princípio 2 Limitar a introdução de tecnologias}

Princípio 3 Obter êxito rápido e identificável

Princípio 4 Experimentar em pequena escala

Princípio 5 Desenvolver um efeito multiplicador
Este princípio facilita a avaliação, a reflexão e a retificação de erros, assim como diminui a magnitude dos possíveis riscos

Não é necessário introduzir muitas técnicas agroecológicas ao mesmo tempo. É mais rápido dominar uma a uma as inovações, consolidando-as e integrando-as pouco a pouco. Deve-se começar por aquelas técnicas que enfrentam e resolvem os maiores problemas produtivos e que, ao mesmo tempo, têm os menores custos iniciais, são fáceis de realizar e levam de maneira mais rápida a um resultado

O entusiasmo é gerador de novas ideias, e as vitórias obtidas são o estímulo mais eficaz. Este princípio busca ser o motor moral na construção e reconhecimento dos progressos do trabalho cotidiano

Experimentar não é outra coisa senão pôr à prova, comprovar, adaptar e adotar, a partir das necessidades, uma nova técnica ou solução. Graças a este princípio, o camponês transforma-se em um ativo experimentador e inovador; e a propriedade, em permanente e rico laboratório. Permite comprovar as tecnologias que servem ou não. Este princípio nos afasta, definitivamente, das receitas genéricas e dos pacotes tecnológicos planejados para todos e para todos os lugares. Proporciona segurança e confiança na tecnologia

A multiplicação entre e pelos próprios camponeses dos resultados e experiências obtidas é a única forma de poder chegar à extensão e massificação deste sistema de produção. [...] Na medida em que os camponeses se transformam em multiplicadores, adquirem mais destreza na produção e na comunicação. $\mathrm{O}$ ensino permite conhecer um tema em profundidade; grande parte deste ensino reside no exemplo vivo, comunicado de camponês a camponês

Fonte: Sosa MA, Jaime AMR, Lozano DRA, et al.14

Já para sua implementação e desenvolvimento prático, o CaC dispõe de um arcabouço de métodos, composto por passos, atores, atividades e ferramentas/instrumentos ${ }^{14}$ (quadros 2 e 3): 
Quadro 2. Passos estruturantes da metodologia Camponês a Camponês

\begin{abstract}
Passo 1 Iniciando o caminho
Começa-se a metodologia nas roças com o diagnóstico rápido dos problemas-chave, para em seguida estabelecer prioridades e identificar as melhorias que possam ser chaves para iniciar as mudanças.

Passo 2 Intercâmbio de experiências Realiza-se o intercâmbio de conhecimentos entre um grupo de camponeses e um promotor que, provavelmente, já tinha soluções para o problema daqueles, porque as experimentou em sua roça. Aqueles que estão com o problema começam a experimentação em pequena escala, para comprovar se a técnica do promotor funciona também em suas próprias roças. Observam êxitos e estabelecem compromissos. São importantes a reciprocidade e a continuidade depois do intercâmbio
\end{abstract}

Passo 3 Ferramentas metodológicas Capacitação para facilitadores e promotores. 0 conhecimento destas ferramentas permitirá utilizá-los em diferentes atividades: oficinas, intercâmbios, jornadas de capacitação e/ou visitas a roças de outros agricultores

Passo 4 Oficina sobre técnicas agroecológicas

Além das técnicas-chave, é necessário experimentar outras tecnologias para garantir que funcionem e deem bons resultados, até dispor de um maior espectro de tecnologias. Há alguns promotores que se animam a experimentar e inovar

Passo 5 Encontro para reforço geral Faz-se uma revisão de todo o processo, a fim de analisar conquistas e dificuldades, identificando as prioridades seguintes. Todos estes passos têm como eixos transversais a equidade de gênero, a agricultura sustentável e a segurança alimentar

Fonte: Sosa MA, Jaime AMR, Lozano DRA, et al. ${ }^{\mathbf{1 4}}$

Quadro 3. Atores, atividades e ferramentas da metodologia Camponês a Camponês

\section{Atores}

Camponeses e Camponesas

Promotor(a) agroecológico

Facilitador(a) da promoção e multiplicação agroecológica

Coordenadores(as) locais, municipais, estaduais e nacionais (dependendo a escala e estrutura de organização camponesa existente)

Parceiros (instituições ou profissionais)

\section{Atividades}

Assembleia de integrantes da organização camponesa

Oficinas de socialização de experiências e construção de novos conhecimentos

Diagnóstico Rápido Participativo

Visitas de trocas de saberes

Intercâmbios de vivências

\section{Ferramentas/Instrumentos}

Demonstrações didáticas (presenciais em roças ou por meios audiovisuais)

Exibição de produtos, sementes, matérias e inovações

Dinâmicas de apresentação, animação e avaliação

Experiência de Banes (identificação participativa de práticas agroecológicas existentes e necessárias e de possíveis promotores(as) agroecológicos(as) nas comunidades rurais)

Outras (representações teatrais, poesias, canções, desenhos, mapas, fotografias, audiovisuais etc.)

Fonte: Sosa MA, Jaime AMR, Lozano DRA, et al. ${ }^{\mathbf{1 4}}$. 
Em suma, a total coerência do $\mathrm{CaC}$ com o conceito de promoção da saúde apresentado pela Carta de Ottawa ${ }^{2}$ e com os conceitos do paradigma da Salutgênese pode ser identificada por meio da descrição dessa metodologia apresentada pela Organização Não Governamental Pan Para el Mundo:

a metodologia Camponês a Camponês é uma forma participativa de promoção e melhoramento dos sistemas produtivos camponeses, partindo do princípio de que a participação e o empoderamento são elementos intrínsecos no desenvolvimento sustentável, que se centra na iniciativa própria e no protagonismo das agricultoras e agricultores 21(22).

\section{Métodos de estruturação e desenvolvimento da metodologia Salutogênese- $\mathrm{CaC}$}

Identificadas a sinergia e complementariedade entre a Salutogênese e o CaC para desenvolver um processo social de promoção da saúde das famílias camponesas expostas a agrotóxicos em Lavras (MG), percebeu-se a possibilidade de estruturar uma metodologia que permitisse a promoção, o fortalecimento e a consolidação dos sentidos cognitivos (compreensão), comportamental (manejo) e motivacional (significado) ${ }^{11-13}$ dos camponeses por meio dos métodos práticos disponibilizados pelo $\mathrm{CaC}^{\mathbf{1 4}}$. Tais métodos deveriam desenvolver, respectivamente, o entendimento do contexto de subjugação do modo de produção dos camponeses pela lógica do agronegócio e também das possibilidades, viabilidades e benefícios gerais (incluindo os sanitários) da agroecologia; a identificação dos recursos agroecológicos existentes em suas propriedades e comunidades e a crença de que eles estão disponíveis para a realização da transição de modelos de produção; e a motivação em querer utilizar seus próprios recursos para a mudança de seu contexto.

Dessa forma, foi formulado um programa de trabalho de campo composto por três etapas, em que, de maneira sequencial, foram realizadas cinco atividades conformadas por ferramentas e instrumentos do CaC que possibilitaram promover (Etapa I), fortalecer (Etapa II) e consolidar (Etapa III) os sentidos que conformam o SOC dos camponeses das comunidades rurais desse município (quadro 4):

Quadro 4. Estruturação proposta para o desenvolvimento da metodologia Salutogênse-CaC

Etapa I - Promoção dos sentidos de Atividade 1-Demonstração didática audiovisual: entendimento do contexto e compreensão, significado e manejo motivação para mudá-lo

Atividade 2 - Primeiro passo da Experiência de Banes: mapeamento dos recursos de saúde

Etapa II - Fortalecimento dos sentidos de compreensão, significado e manejo

Etapa II - Consolidação dos sentidos de compreensão, significado e manejo
Atividade 3 - Intercâmbio camponês: visita para troca de entendimentos, motivações e técnicas

Atividade 4 - Testemunhos do intercâmbio camponês: multiplicação das compreensões, crenças e motivações

Atividade 2 - Concretização da Experiência de Banes: construção coletiva do Repertório de Recursos de Saúde 
A zona rural de Lavras, local de desenvolvimento da metodologia apresentada, é formada por 71 comunidades, sendo as de menor número de moradores 'agrupadas', pelo governo municipal, às 19 maiores, para a organização e prestação dos serviços públicos de saúde, de agricultura, de infraestrutura etc. Assim, essas 19 comunidades foram consideradas no planejamento de desenvolvimento da metodologia (realizada entre os meses de maio e setembro de 2017), tendo o trabalho a Pesquisa-Ação 22 como desenho e a Análise de Conteúdo ${ }^{23}$ como método de análise dos dados registrados (por meio de equipamento de gravação de áudio e diário de campo).

Para o desenvolvimento da primeira etapa, foram programados encontros nas 19 comunidades rurais, sendo a forma de realização acordada com os Agentes Comunitários de Saúde (ACS) da Equipe de Saúde da Família da Zona Rural (EqSF) durante reunião mensal deles (abril de 2017) e, por telefone, com lideranças das comunidades onde não há cobertura da EqSF. Os camponeses foram informados da realização e convidados a participar desses primeiros encontros por meio de comunicação direta realizada tanto pelos ACS e lideranças das comunidades quanto pelo pesquisador. Para isso, o pesquisador utilizou os contatos telefônicos registrados durante os trabalhos de campo do mestrado 4 (desenvolvido nas mesmas 19 comunidades rurais). Foram convidados, então, os moradores contatados nas ligações, e foi requisitado que estes convidassem seus familiares, vizinhos e conhecidos da comunidade. Já para o desenvolvimento da segunda e terceira etapas, os camponeses foram convidados pelo pesquisador por meio dos contatos telefônicos fornecidos na primeira etapa.

Além disso, foram levadas em consideração as informações dos ACS, lideranças e camponeses sobre a dinâmica laboral/social nas comunidades para definir os dias, horários e locais dos encontros das Etapas I e III e também para programar a data da viagem para a visita de troca de saberes em que consiste a Etapa II (as especificidades de seleção para esta etapa serão destacadas no relato da experiência do tópico Resultado). Dessa forma, para facilitar e estimular a participação dos camponeses, foram definidos dias de atendimento da EqSF, dias de missa/culto ou dias de semana após o horário de trabalho (em bares locais, por exemplo), conforme as características e locais considerados como pontos de encontro em cada comunidade. Os moradores que não haviam sido contatados anteriormente e que estavam presentes nas ocasiões dos encontros também foram convidados a integrar as atividades das Etapas I e III.

Por fim, não foi necessária a realização de piloto para o desenvolvimento da metodologia em Lavras, uma vez que o trabalho de campo do mestrado 4 , o trabalho de devolução de seus resultados e conclusões e também a produção e gravação do documentário curta-metragem ' $\mathrm{O}$ Uso INSeguro dos Agrotóxicos' ${ }^{\mathbf{2 4}}$, desenvolvidos nas comunidades desse município, permitiram a construção de credibilidade e vínculo entre o pesquisador responsável e os camponeses e a construção dos subsídios necessários (como o conhecimento geral das características das comunidades e seus moradores e das especificidades de cada comunidade) para a adoção desta pesquisa-ação estruturada pela metodologia Salutgênese-CaC.

\section{Resultado - a experiência da metodologia Salutogênese-CaC}

\section{Etapa I: Promoção dos sentidos de compreensão, significado e manejo}

\section{ATIVIDADE 1 - DEMONSTRAC̣ÃO DIDÁTICA AUDIOVISUAL: ENTENDIMENTO DO CONTEXTO E MOTIVAC̣̃̃O PARA MUDÁ-LO}

Essa primeira atividade buscou trabalhar dois dos três fatores descritos por Antonovsky ${ }^{11,12}$ como fundamentais para direcionar a promoção da saúde e o sentido pessoal e comunitário 
para as experiências de vida positivas e para a saúde: o componente de compreensão (desvelamento e apropriação dos porquês e de como se conforma o contexto de injustiça em que vivem) e o componente de significado (ver sentido e motivar-se em buscar as possibilidades de mudança deste contexto).

Para o desenvolvimento da atividade, foi utilizado o método da Demonstração Didática que, segundo a metodologia $\mathrm{CaC}$,

trata-se de um tipo de instrumento que serve para demostrar, de maneira visual e prática, um processo negativo ou positivo. A demonstração deve ser sempre acompanhada de uma explicação e do debate entre os presentes ${ }^{\mathbf{1 4}(71)}$.

No trabalho desenvolvido em Lavras, foi apresentado, como meio de visualização e estímulo ao debate sobre o contexto e as possibilidades locais, o documentário curta-metragem 'O Uso INSeguro dos Agrotóxicos'24. Esta ferramenta audiovisual foi produzida para popularizar e facilitar diálogos sobre os resultados e conclusões da dissertação de mestrado ' $\mathrm{O}$ agricultor familiar e o uso (in)seguro de agrotóxicos no município de Lavras, $\mathrm{MG}^{\mathbf{4}}$. O documentário aborda, na primeira parte do vídeo, a desconstrução do paradigma do 'uso seguro’ e do modelo do agronegócio para o contexto das propriedades e comunidades camponesas, e, na segunda parte, as viabilidades e benefícios da agroecologia.

Logo após a exibição, todos os presentes foram formalmente convidados a integrar o que foi chamado Encontro de Promoção da Saúde (EPS) de sua comunidade. No âmbito dos EPS dessa primeira atividade, foram realizadas rodas de diálogo sobre os temas apresentados pelo documentário. Os debates foram estimulados por perguntas, elaboradas conforme o momento da discussão, que buscavam identificar se os participantes compreendiam e concordavam com a existência de um modelo de produção dominante que causa danos sanitários, sociais, familiares, econômicos e culturais em suas comunidades e, ainda, levantar as prioridades, aspirações, necessidades, vontades, intenções e/ou desejos dos camponeses em relação à possibilidade de mudança para uma forma de produção mais saudável, rentável e justa.

Não foi necessário realizar seleção dos integrantes dos EPS, pois a intenção da atividade foi fortalecer os sentidos de compreensão e de significado de todos os camponeses presentes nesse encontro. A variação do número de participantes em cada comunidade não dificultou o desenvolvimento da atividade, uma vez que a condução da discussão e a forma de coleta de dados foram de simples execução.

\section{ATIVIDADE 2 - PRIMEIRO PASSO DA EXPERIÊNCIA DE BANES: MAPEAMENTO DOS RECURSOS DE SAÚDE}

Essa atividade deu início ao trabalho de desenvolvimento nas comunidades rurais do componente de manejo, descrito por Antonovsky ${ }^{11,12}$ como o entendimento e a crença dos moradores das comunidades de que os recursos necessários para lidar com qualquer situação de dificuldade, injustiça e/ou mudança estão presentes, disponíveis e acessíveis para utilização na própria comunidade.

Nesse sentido, nessa atividade, foi realizado o mapeamento dos recursos agroecológicos presentes nas comunidades rurais de Lavras. Para esse mapeamento, foi utilizada uma adaptação da ferramenta do $\mathrm{CaC}$ conhecida como Experiência de Banes ${ }^{\mathbf{1 4}}$, que consiste na realização de um levantamento participativo e didático das práticas agroecológicas aplicadas nas propriedades das comunidades envolvidas no processo de transição de modelos de produção. Para a aplicação nas comunidades rurais de Lavras, a Experiência de Banes foi estruturada na forma de questionário de fácil entendimento e preenchimento pelos participantes. Essa estruturação se fez necessária devido ao contexto de baixa escolaridade formal encontrado na zona rural do município ${ }^{4}$, o que poderia levar à perda de 
dados por dificuldade de leitura e escrita caso a Experiência de Banes fosse aplicada em seu formato original, em que as práticas agroecológicas são relacionadas de forma escrita em uma cartolina ou quadro, e os camponeses escrevem em um papel, após explicações feitas por um facilitador, as práticas que utilizam ${ }^{\mathbf{1 4}}$.

Dessa forma, trabalhando-se com os EPS já conformados na primeira atividade dessa etapa, foi utilizado um questionário de autopreenchimento composto por 50 perguntas, no qual cada página continha apenas duas perguntas, em letras grandes, a respeito do conhecimento e utilização de práticas agroecológicas nas propriedades dos camponeses presentes.

Para a aplicação, a mesma página do questionário que estava sendo aplicada/preenchida foi projetada em local visível por meio de um projetor de imagens. O pesquisador utilizou a projeção tanto para explicar e sanar dúvidas, sobre cada uma das práticas descritas nas perguntas, quanto para indicar as possíveis opções de escolha para a marcação pelos camponeses. As opções foram: 'Sim', que foi representada no questionário por um sinal gráfico afirmativo (dedo polegar voltado para cima), e 'Não', que apresentou ao seu lado um sinal gráfico negativo (dedo polegar voltado para baixo).

O tratamento dos dados levantados por meio do questionário integrou a Atividade 5 da Etapa III, onde será abordado.

\section{Etapa II: Fortalecimento dos senti- dos de compreensão, significado e manejo}

\section{ATIVIDADE 3 - INTERCÂMBIO CAMPONÊS: VISITA PARA TROCA DE ENTENDIMENTOS, MOTIVAC̣ÕES E TÉCNICAS}

Apesar de terem sido promovidos e visibilizados nas atividades da primeira etapa do trabalho, os sentidos de compreensão, manejo e significado dos camponeses de Lavras - fundamentais para que assumam o protagonismo e a disposição para mudar de forma ampla o modelo de produção hegemônico por meio da transição agroecológica - ainda careciam de um exemplo prático para fortalecê-los perante o ofuscamento causado pelo contexto de dependência desses camponeses em relação à lógica, técnicas, insumos e profissionais de órgãos e instituições voltadas para o agronegócio.

É nesse sentido que essa etapa buscou o fortalecimento do SOC de camponeses das comunidades rurais de Lavras apresentando um exemplo prático das vantagens e viabilidades do modelo de produção agroecológico em uma propriedade camponesa, em que os insumos externos não são necessários, e o equilíbrio produção-ambiente é capaz de resgatar a cultura, o ambiente e a dignidade local, ao mesmo tempo em que gera boa produtividade e lucratividade.

A atividade dessa etapa consistiu, portanto, em realizar uma Visita de Intercâmbio ${ }^{\mathbf{1 4}}$ de representantes das comunidades a uma família de camponeses que fez a transição de modelos de produção. A propriedade familiar onde foi realizada essa visita é a de uma família do município de Claraval (MG), que já havia sido apresentada indiretamente aos camponeses de Lavras por meio do documentário curta-metragem exibido na Atividade 1 da Etapa I. Essa visita buscou possibilitar tanto a troca de entendimentos sobre a injustiça e inviabilidade do modelo agroquímico hegemônico de produção introjetado em suas produções e modo de vida quanto a troca de motivações e técnicas para a mudança para o modelo agroecológico.

Os primeiros convidados para participar da visita foram os ACS da EqSF rural. Em seguida, foram selecionados e convidados representantes camponeses das comunidades rurais do município. A seleção foi feita por conveniência e levou em consideração critérios de orientação (não hierarquizados e flexíveis frente à realidade de cada comunidade e ao cotidiano dos camponeses), tais como: 'pontuação' na Experiência de Banes, aplicada na Atividade 2 da Etapa I; bom relacionamento com os demais camponeses e entusiasmo com a transição agroecológica, apresentados durante as atividades da Etapa I; e disponibilidade de se ausentar de 
Lavras por um dia inteiro de trabalho na data disponibilizada pela família de Claraval.

\section{Etapa III: Consolidação dos senti- dos de compreensão, significado e manejo}

\section{ATIVIDADE 4 - TESTEMUNHOS DO INTERCÂMBIO CAMPONÊS: MULTIPLICAC̣ÃO DAS COMPREENSÕES, CRENC̣AS E MOTIVAC̄ÕES}

Após a realização de etapas de trabalho em que foram promovidos e fortalecidos os sentidos de compreensão, significado e manejo, partiu-se para a Etapa III, na qual se buscou consolidar o SOC dos camponeses e dar materialidade e acessibilidade aos recursos agroecológicos presentes em suas propriedades e comunidades. Dessa forma, a Atividade 4 consistiu em um EPS para o compartilhamento e discussão, com os demais camponeses das comunidades rurais de Lavras, das compreensões, crenças e motivações adquiridas pelos participantes da atividade de troca de saberes em Claraval.

Para o desenvolvimento do EPS, foi utilizado o instrumento do $\mathrm{CaC}$ chamado Testemunhos ${ }^{\mathbf{1 4}}$, em que os representantes das comunidades rurais que participaram da visita (incluindo os ACS) e também o pesquisador relataram suas experiências e vivências, multiplicando suas novas impressões sobre o contexto das comunidades; sobre a agroecologia; sobre o que eles identificaram como novos tipos de recursos presentes nas propriedades e comunidades; e sobre as motivações e a necessidade de desenvolvimento de novas práticas de cultivo, de organização camponesa e de novas parcerias em prol da transição agroecológica.

Os camponeses presentes, mesmo os que não compareceram à primeira etapa de trabalho e não conformaram o EPS naquela ocasião, foram convidados a integrar o EPS da Etapa
III, âmbito dos relatos e discussões dessa atividade. Pelos mesmos motivos da Atividade 1 da Etapa I, não foi realizada seleção dos integrantes do EPS nem houve critério de exclusão para conformar esse espaço aberto e coletivo. Para estimular os relatos e as discussões, foram exibidas fotografias realizadas durante a visita em Claraval e, nas comunidades onde houve participação no EPS de camponeses que não haviam participado da Etapa I, foi novamente exibida a ferramenta audiovisual ' $\mathrm{O}$ Uso INSeguro dos Agrotóxicos' $\mathbf{2 4}$ como forma de contextualização e 'nivelamento' das participações nos debates.

\section{ATIVIDADE 5 - CONCRETIZAÇÃO DA EXPERIÊNCIA DE BANES: CONSTRUÇÃO COLETIVA DO REPERTÓRIO DE RECURSOS DE SAÚDE}

Compartilhadas, discutidas e multiplicadas as experiências, ideias e condições locais para a realização da transição agroecológica, buscou-se, por meio dessa atividade, desenvolver a materialização, a instrumentalização e a disponibilização dos recursos identificados pelos próprios camponeses na aplicação da Experiência de Banes na Etapa I. A presente atividade buscou, assim, a compreensão e a motivação dos camponeses em relação à acessibilidade dos recursos existentes em suas propriedades e comunidades e a consolidação da percepção de que o manejo de tais recursos em prol da transição para um modelo de produção mais justo e da promoção da saúde local dependem da decisão e organização deles mesmos.

Para isso, os recursos identificados por meio da aplicação do questionário na Atividade 2 foram tabulados e estruturados conforme o exemplo da tabela $\mathbf{1}^{25}$. Assim, foi possível tornar visível quais práticas agroecológicas estão presentes em cada uma das comunidades, propriedades e camponeses. 
Tabela 1. Planilha de resultados da Experiência de Banes em uma comunidade rural fictícia

\begin{tabular}{|c|c|c|c|c|c|c|c|c|c|}
\hline $\begin{array}{l}\text { Práticas } \\
\text { agroecológicas }\end{array}$ & Compostagem & $\begin{array}{r}\text { Rotação } \\
\text { de cultivos }\end{array}$ & $\begin{array}{r}\text { Associação } \\
\text { de cultivos }\end{array}$ & $\begin{array}{r}\text { Aplicação } \\
\text { de matéria } \\
\text { orgânica }\end{array}$ & $\begin{array}{r}\text { Cobertura } \\
\text { do solo }\end{array}$ & $\begin{array}{r}\text { Uso de } \\
\text { plantas } \\
\text { repelentes }\end{array}$ & $\begin{array}{c}\text { Uso de } \\
\text { adubo } \\
\text { verde }\end{array}$ & $\begin{array}{r}\text { Integração } \\
\text { animal }\end{array}$ & TOTAL \\
\hline João $P$. & $x$ & $x$ & & & & & & & 2 \\
\hline José R. & $x$ & $x$ & $x$ & $x$ & $x$ & & $x$ & $x$ & 7 \\
\hline Maria D. & $x$ & $x$ & & $x$ & & & & $x$ & 3 \\
\hline Glória A. & $x$ & $x$ & $x$ & $x$ & $x$ & & & $x$ & 6 \\
\hline Paulo M. & $x$ & & & & & & & $x$ & 2 \\
\hline TOTAL & 5 & 4 & 2 & 3 & 2 & 0 & 1 & 4 & \\
\hline
\end{tabular}

Fonte: Anap - Folleto de la metodología de Campesino a Campesino25(9)

Como se pode perceber no exemplo apresentado, a concretização da Experiência de Banes permite a visualização dos conhecimentos e práticas presentes na comunidade e que podem ser compartilhadas com agricultores da mesma ou de outras comunidades (colunas Compostagem, Rotação de Cultivos, e Integração animal); conhecimentos e práticas que podem ser aprimorados (colunas Uso de plantas repelentes e Uso de adubo verde); e os camponeses que apresentam maiores conhecimentos em práticas agroecológicas e que, por isso, apresentam potencial para serem Promotores(as) Agroecológicos(as) em suas comunidades (linhas José R. e Glória A.) ${ }^{25}$.

O trabalho, então, de construção coletiva do que foi chamado Repertório de Recursos de Saúde das comunidades se deu na sequência do mesmo EPS da Atividade 4, utilizando-se como instrumentos visuais as tabelas estruturadas com os recursos agroecológicos coletados na primeira etapa de trabalho, identificados pelos próprios camponeses. Os instrumentos visuais de cada comunidade, confeccionados por meio da colagem em cartolinas das tabelas de recursos impressas, foram apresentados para que os participantes pudessem reconhecer e acessar as práticas agroecológicas que conhecem e utilizam.

Assim, nesse momento, cada recurso contido nas tabelas foi reapresentado e reexplicado pelo pesquisador para que os camponeses que não estavam presentes na Etapa I pudessem complementá-las e para que os camponeses que já integravam as tabelas pudessem atualizá-las ou corrigi-las. Dessa forma, ao final desta atividade coletiva de reestruturação e validação das tabelas de recursos, estes passaram a ser considerados como os Repertórios de Recursos de Saúde de cada comunidade.

\section{Discussão}

A definição de estruturar como etapas de trabalho a promoção, o fortalecimento e a consolidação dos sentidos de compreensão, significado e manejo da Salutogênese teve como objetivo dar sustentação teórica ao conceito de promoção da saúde, utilizado para o desenvolvimento da pesquisa-ação com populações camponesas expostas a agrotóxicos nas comunidades rurais de Lavras. Já a estruturação das atividades de trabalho, em cada etapa, por meio de instrumentos e ferramentas da metodologia social $\mathrm{CaC}$ foi idealizada e aplicada tanto para suprir a carência de métodos práticos da Salutogênese quanto para dar a esse processo de promoção da saúde seu caráter agroecológico, horizontal e de protagonismo camponês, sendo estes 
componentes de construção de autonomia das famílias camponesas ${ }^{8-10,14}$.

A realização das Atividades 1, 3 e 4 como um eixo convergente que integra e interconecta o processo de promoção, fortalecimento e consolidação desses sentidos buscou, principalmente, desenvolver os sentidos pessoais e comunitários que levam à compreensão de seu contexto e à motivação para mudá-lo. Nesse sentido, vale destacar que os trabalhos de devolução dos resultados e conclusões do mestrado 4 e de produção e exibição do documentário curta-metragem sobre a impossibilidade do paradigma de proteção da saúde por meio do 'uso seguro' de agrotóxicos e sobre as possibilidades e benefícios gerais da agroecologia tanto permitiram a visualização, o debate e o reconhecimento do contexto de perigo e dependência em relação ao modelo agroquímico de produção quanto demonstraram que os compromissos pós-pesquisa de devolução e popularização dos conhecimentos científicos desenvolvidos (no caso, por meio da dissertação) desempenham um papel fundamental na construção de credibilidade de pesquisadores e da própria ciência/academia, de vínculos edificadores com sujeitos e comunidades pesquisadas e de subsídios para adotar metodologias sociais subsequentes de pesquisa-ação.

Além disso, o intercâmbio camponês para troca de saberes agroecológicos e de entendimento de contextos e suas multiplicações nas comunidades rurais, por meio do compartilhamento das compreensões, crenças e motivações adquiridas pelos representantes que realizaram a visita, mostraram-se como atividades determinantes para formar a convicção na viabilidade do modelo de produção da agroecologia e a disposição dos camponeses em construírem o processo de transição.

Já as Atividades 2 e 5 buscaram desenvolver a crença de que os camponeses de Lavras dispõem dos recursos necessários para realizar esse processo de transição agroecológica. Essencialmente complementares, essas atividades foram alocadas na estrutura da metodologia de forma que entre seu momento de promoção - por meio do contato (explicações do pesquisador, projeção de imagens e questionário) e da identificação dos conhecimentos e práticas agroecológicas disponíveis em suas propriedades - e seu momento de consolidação dos sentidos de compreensão, significado e manejo - por meio do reconhecimento, validação e apropriação destas práticas - fosse desenvolvida a referida convicção dos camponeses por meio das Atividades 3 e 4. Dessa forma, a discussão e percepção sobre as práticas agroecológicas que têm disponíveis, durante a realização da Atividade 2, e a visualização e validação conscientes das tabelas com as informações sobre recursos agroecológicos de suas propriedades e comunidades, na Atividade 5, permitiram a apropriação destas tabelas de fato como Repertórios de Recursos de Saúde a serem utilizados como instrumentos de um processo autônomo de transição de modelos de produção.

Assim, essa metodologia de intervenção colaborativa e democrática sobre a realidade das comunidades rurais, desempenhada coletivamente entre os sujeitos camponeses e o pesquisador ${ }^{22}$, permitiu, ao longo das etapas e atividades, a obtenção de um conjunto de dados que foram tratados e classificados conforme categorias que permitiram deduzir, de maneira lógica, diversos conhecimentos sobre os camponeses e suas comunidades ${ }^{23}$. Nesse sentido, foi possível alcançar resultados sociais e sanitários eficazes (a serem apresentados em publicações futuras) em um contexto de forte dominação ideológica e prática pelo modelo do agronegócio e de ausência de condições favoráveis, como estrutura organizativa camponesa prévia, processos de transição agroecológica em andamento e/ou apoio público para tal organização e transição.

\section{Considerações finais}

No decorrer do processo de elaboração da metodologia Salutogênse-CaC, o cuidado na escolha e estruturação das etapas e atividades de trabalho teve como objetivo operacionalizar o conceito de promoção da saúde, descrito pela Carta de Ottawa ${ }^{2}$, para o contexto dos 
camponeses de Lavras (MG). Na prática, a interconexão dos conceitos e procedimentos sociológicos da Salutogênese e do Camponês a Camponês correspondeu à identificação, assimilação, disponibilização e apropriação dos conhecimentos e práticas agroecológicas (recursos de saúde) presentes em suas propriedades e comunidades, do contexto em que vivem e da possibilidade de construção de uma nova realidade por meio de seus próprios recursos.

A partir dessa operacionalização teórico-prática, foram desenvolvidos constructos subjetivos, como a sustentação da viabilidade da agroecologia como modelo de produção para a melhoria das condições de vida e saúde nas propriedades e comunidades rurais, e instrumentos como o Repertório de Recursos de Saúde, que vem orientando o amplo processo de transição agroecológica e de organização camponesa em Lavras.

Ao ser utilizada com êxito para dar início e desenvolver tal processo social de promoção da saúde, a metodologia relatada neste trabalho se apresenta como ferramenta para ações e pesquisas em contextos semelhantes em outras localidades do Brasil, com vistas à mudança da situação sanitária vulnerável a que estão expostos os camponeses que utilizam agrotóxicos no País.

\section{Colaboradores}

Pedro Henrique Barbosa de Abreu e Herling Gregorio Aguilar Alonzo contribuíram de forma igualitária para a concepção e execução deste artigo.

\section{Referências}

1. Czeresnia D, Freitas CM. Promoção da Saúde: conceitos, reflexões e tendências. Rio de Janeiro: Fiocruz; 2009

2. Brasil. Ministério da Saúde. Projeto Promoção da Saúde. Brasília: Ministério da Saúde; 2001.

3. Buss PM. Uma introdução ao conceito de Promoção da Saúde. In: Czeresnia D, Freitas CM, organizadores. Promoção da Saúde: conceitos, reflexões e tendências. Rio de Janeiro: Editora Fiocruz; 2009. p. 1942 .

4. Abreu PHB. O agricultor familiar e o uso (in)seguro de agrotóxicos no município de Lavras, MG [dissertação]. [Campinas]: Universidade Estadual de Campinas; 2014. p. 205.

5. Carneiro FF, Augusto LGS, Rigotto RM, et al., organizadores. Dossiê ABRASCO: um alerta sobre os impactos dos agrotóxicos na saúde. Rio de Janeiro: EPSJV; 2015.

6. Rigotto RM, Rosa IF. Agrotóxicos. In: Caldart RS, Pereira IB, Alentejano P, et al., organizadores. Dicionário da educação do campo. Rio de Janeiro: Expressão Popular; 2012. p. 86-94. 
7. Brasil. Ministério da Saúde, Secretaria de Vigilância em Saúde, Departamento de Vigilância em Saúde Ambiental e Saúde do Trabalhador. Relatório Nacional de Vigilância em Saúde de Populações Expostas a Agrotóxicos: Agrotóxicos na ótica do Sistema Único de Saúde [internet]. [Brasília, DF]: Ministério da Saúde; 2016 [acesso em 2018 mar]. Disponível em: http:// portalarquivos2.saude.gov.br/images/pdf/2016/dezembro/05/Relatorio-Nacional-de-VSPEA-vol-1.pdf.

8. Navolar TS, Rigon AS, Philippi JMs. Diálogo entre agroecologia e promoção da saúde. Rev. bras. promoç. Saúde (Impr.). Fortaleza. 2009 nov 16; 23(1):69-79.

9. Azevedo E, Pelicioni MCF. Promoção da saúde, sustentabilidade e agroecologia: uma discussão intersetorial. Saúde Soc. 2011 mar 1; 20(3):715-29.

10. Azevedo E, Pelicioni MCF. Agroecologia e promoção da saúde no Brasil. Rev. panam. salud pública. 2011 set 28; 31(4):290-95.

11. Antonovsky A. Unraveling the mystery of health: how people manage stress and stay well. San Francisco: Jossey-Bass; 1987.

12. Antonovsky A. The salutogenic model as a theory to guide health promotion. Health promot. internation. Eynsham. 1996; 11(1):11-18.

13. Eriksson M. Lindsttröm B. A salutogenic interpretation of the Ottawa Chartrer. Health promot. internation. Eynsham. 2008 jul; 23(2):190-99.

14. Sosa MA, Jaime AMR, Lozano DRA, et al. Revolução agroecológica: o movimento de camponês a camponês da ANAP em Cuba. São Paulo: Expressão Popular; 2013.

15. Giménez EH. Campesino a Campesino: Voces de Latinoamérica Movimiento Campesino para la Agricultura Sustentable. Managua: SIMAS; 2008.

16. Nils M, Sanchez M. Teaching the territory: agroecological pedagogy and popular movements. Agric. human values [internet]. $2018 \mathrm{fev} 15$ [acesso em 2018 dez 6]; 35:1-16. Disponível em: https://link.springer. com/article/10.1007/s10460-018-9853-9.

17. Lacerda VR, Pontes ERJC, Queiroz CL. Relação entre senso de coerência materno, condições socioeconômicas e percepção da saúde bucal. Estud. psicol. Campinas. 2011 set 14; 29(2):203-08.

18. Eriksson M. Lindsttröm B. Antonovsky's sense of coherence scale and its relation with quality of life: a systematic review. J. epidemiol. community health. 2007 jan 23; 61:938-44.

19. Eriksson M. Lindsttröm B. Antonovsky's sense of coherence scale and the relation with health: a systematic review. J. epidemiol. community health. 2005 dez 5; 60:376-81.

20. Bienert M, Herrera ML, Morales YA, et al. De Campesino a Campesino: metodología, pedagogía y movimiento para el desarrollo sostenible de la agricultura familiar campesina. Managua: EDISA; 2010.

21. Pan Para el Mundo. Construyendo procesos De Campesino a Campesino. Lima: ESPIGAS; 2006.

22. Thiollent M. Metodologia da pesquisa-ação. São Paulo: Cortez; 2011.

23. Bardin L. Análise de conteúdo. São Paulo: Edições $70 ; 2011$.

24. Abreu PHB, Alonzo HGA. O Uso INSeguro dos Agrotóxicos. YouTube [internet]. 2016 Set [acesso em 2018 fev 28]. Disponível em: https://www.youtube.com/ watch?v=HVdZV4JaKAs

25. Asociación Nacional de los Agricultores Pequeños de Cuba. Folleto de la metodología de Campesino a Campesino. La Habana: Imprenta MINAG; 2015.

Recebido em 08/11/2017

Aprovado em 11/03/2018

Conflito de interesses: inexistente

Suporte financeiro: não houve 